\title{
AN ASSESSMENT OF THE QUALITY OF CARE GIVEN TO, AND HYGIENE ON PATIENTS AT A TEACHING HOSPITAL IN NAMIBIA
}

\section{A VAN DYK and LF SMALL: Project leaders}

\section{SUMMARY}

An assessment was done during 1991 to evaluate the quality of care with regard to mouth hygiene rendered to patients in a teaching hospital in Namibia.

The sample was drawn from nine wards. By means of a type of quota sampling, the patients were categorised as dependent, interdependent or independent.

The nursing process was used as a framework for the study. From the assessment it became evident that no policies existed with regard to oral hygiene.

Planning was not in every case based on assessment, and it seemed that when planning(s) were done, it was not always implemented. Record keeping was the aspect most poorly attended to.

\section{OPSOMMING}

Gedurende 1991 is die gehalte van sorgverlening met betrekking tot mondhigiëne geevalueer by pasiënte in ' $n$ opleidingshospitaal.

Die steekproef is gedoen in nege sale d.m.v. ' $n$ tipe kwota steekproef. Die pasiënte in die steekproef.in die nege sale is gekategoriseer in een van drie kategorieë naamlik: afhanklik, interafhanklik en onafhanklik.

Die verpleegproses is as raamwerk vir die studie gebruik. Uit die beoordeling het dit geblyk dat nie een van die sale oor enige beleid rakende mondhigiëne beskik nie.

Indien beplanning uitgevoer is, is dit nie altyd gebasseer op beraming nie. Beraming weer is nie altyd opgevolg met implementering nie. Rekordhouding was een van die aspekte wat die minste nagekom is.

\section{INTRODUCTION AND PROBLEM STATEMENT}

Oral hygiene is necessary for the physical and psychological well being of the human being. It includes cleaning of the teeth, gums, palate and inner cheeks. All patients, no matter at what level of dependency, need mouth care.

The problem for this study centred around the following question:- How effective is oral hygiene for all categories of patients in the hospital?

Although mouth care is an integral part of the nursing curriculum, problems regarding the effectiveness of mouth care rendered were detected during clinical rounds and teaching in the wards.

It was observed that although mouth care was identified as a very important basic need, the follow up care was not done at all, or if done; not effectively.

\section{OBJECTIVES}

* To determine if:- there was a ward policy conceming oral hygiene

* Assessment on oral hygiene on patients was done on a regular basis

* Oral hygiene was part of the nursing care plan

* Correct methods of mouth care procedures are implemented

* The condition of the mouth is evaluated regularly

\section{FRAMEWORK}

The following steps of the nursing process were used as framework for the study: * assessment, planning, implementation, evaluation and record keeping.

\section{DEFINITION AND TERMS}

Patient: For the purpose of this study patient means any person admitted to hospital for treatment, care or observation.

\section{LITERATURE REVIEW}

The literature review was undertaken to indicate the importance of oral hygiene. The person who must assess and attend to this basic need is the nurse.

A dirty mouth does not only lead to complications but also causes the patient discomfort. It must therefore be avoided. Certain clients are prone to oral problems often because of lack of knowledge or the inability to maintain oral hygiene. Among these are seriously ill, confused and dehydrated patients (Kozier \& Erb, 1987:927).

A dirty mouth in patients who are unable to attend to their own oral hygiene is always a sign of neglect on the part of the nursing staff. If not attended to properly, a dirty mouth can cause major complications. Patients must be made aware of proper oral hygiene through health education. Dental care should be based on the principles of primary health care, with community participation and a basis towards the prevention of disease rather than the treatment of its effects. Nursing care with regard to oral hygiene includes health education. Diseases such as dental caries, periodontal disease and to some extent, oral cancer are preventable (Davies, 1991:171).

Dental health education with special reference to methods of oral hygiene aimed at preventing complications, is of utmost importance in nursing care. The nursing process should form the framework for planning and implementing nursing care. The nursing process is a systematic, rational method of planning and providing nursing care. Its goal is to identify a client's actual or potential health care needs, establish plans to meet the identified needs, and to deliver specific nursing interventions to meet those needs. (Kozier and Erb, 1987:214).

Vlok \& Lochner (1983:80) state that general directions regarding the care of the mouth are: 


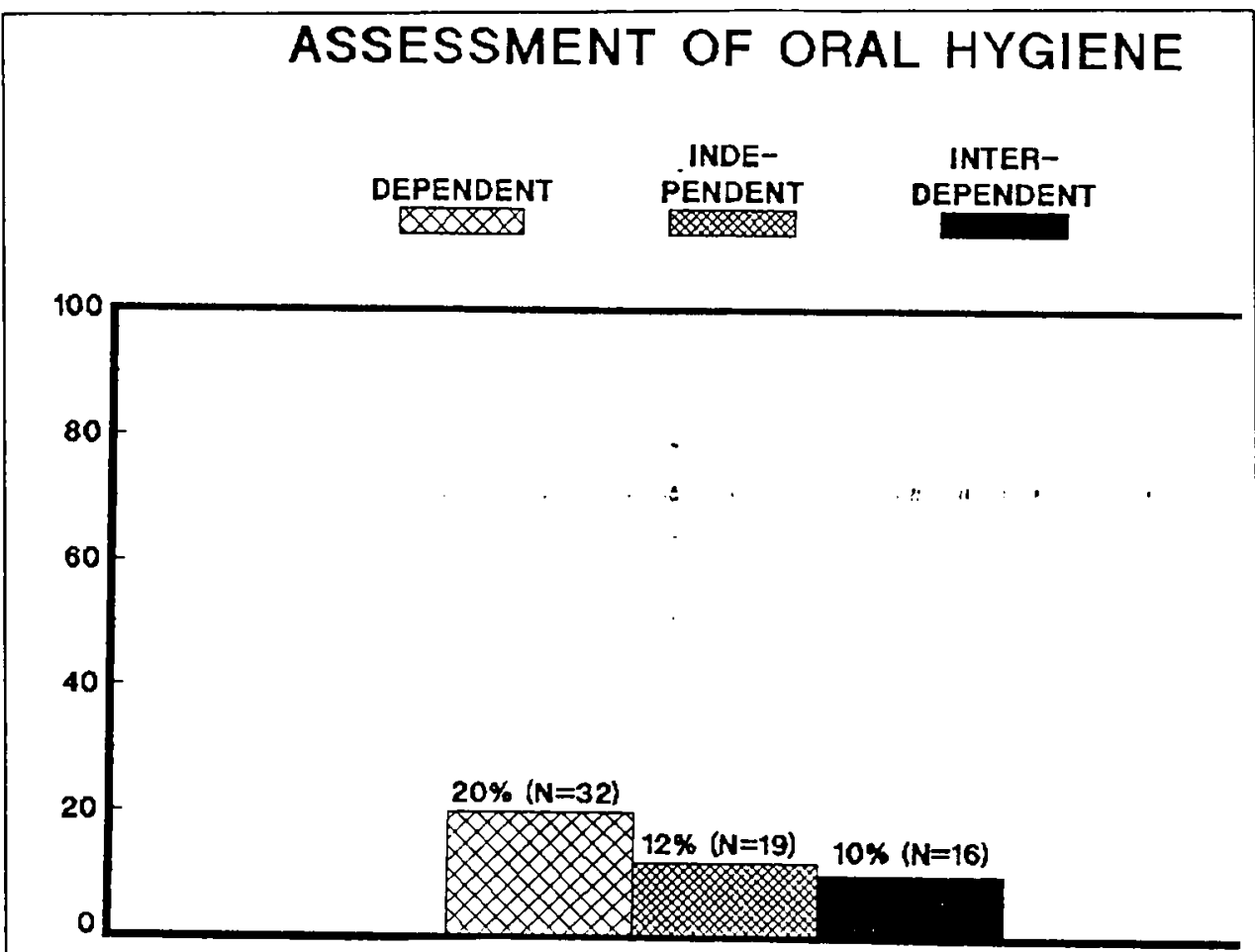

* (N = ASSESSMENTS DONE OUT OF A TOTAL OF 162)

\section{FIGURE 1}

* Brushing the teeth and rinsing the mouth twice a day are sufficient to keep the mouth healthy in the majority of patients

* Where a toothbrush is not available, a mixture of table salt and sodium bicarbonate can be used as a dental powder, this being applied with a piece of material

* Patients should be given the opportunity to clean their teeth after supper

* A furred tongue can be cleaned with diluted peroxide and then washed with a deodorant mouth wash

* If a patient is without teeth, he should rinse his mouth at least twice a day and more frequently if it is inflamed or if the case of halitosis is present.

* Dentures are cleaned twice a day under running water

* If the patient has a splinted jaw, or is unable to open his mouth, the mouth can be cleaned by irrigation

* When patients require special mouth care, a surgically clean procedure is carried out two to four times a day. A basic sterile mouth pack is used.

\section{METHODOLOGY}

The investigation was a descriptive survey.

The population consisted of all the patients in the academic hospital. Nine wards were selected by the nine nursing education students. Each selected a ward. They then selected the nine

The total number of patients observed were eighty one; twenty-seven independent, dependent patients.

\section{INSTRUMENT}

A closed-ended questionnaire consisting of 36 items was used. The items on the questionnaire implementation, evaluation and record keeping.

Questions were responded to by a yes, no or not applicable.

Because the dependency level of the patient is of thus:-DEPENDENCY LEVELS conscious and can be interviewed. own basic needs but requires assistance. sufficient. only record keeping evaluated. e) Unconscious patients were classed with dependent patients.

The instrument was tested on ten patients in two hospitals. Minimal adjustments were made in some cases. The instrument showed face and content validity.

\section{DATA COLLECTION}

The study was done for three consecutive days by the nine nursing education students. Two observations and interviews were done each day on all patients selected for the study (N 81). A total of 486 observations were completed

In the event of patients being confused, unconscious, or unable to communicate, use was made of observations and available written records.

\section{DATA ANALYSIS}

$\mathrm{X}=\mathrm{a} /(\mathrm{a}+\mathrm{b}) \times 100$ where $\mathrm{X}$ is percentage of delivered care, $a$ is 'yes' response and b was 'no' response

The following scale was used to determine the type of care patients received.

$\begin{array}{lc}\text { excellent care } & 95-100 \% \\ \text { good care } & 75-94 \% \\ \text { poor care } & 50-74 \% \\ \text { very poor } & 0-49 \%\end{array}$

\section{FINDINGS} twenty-seven interdependent and twenty-seven were divided into assessment, planning, upmost importance when performing oral hygiene, it was decided to subdivide the above sections into dependency levels,

a) Dependent: Patient is dependent on nursing staff to accommodate basic needs but is

b) Interdependent: Patient is able to attend to

c) Independent: Patient is completely self

d) Confused: Unable to interview patient, i.e.

\section{(Ward Policy)}

The first item determined the presence of a ward policy regarding oral hygiene. Although in general, most wards determined special indications for oral hygiene e.g. recovering from anaesthesia, following facial maxillary surgery - no policy existed regarding recommended frequency intervals, and the prescribed solutions to be used.

Out of the nine wards visited, none had a particular policy regarding oral hygiene available or insufficient guidelines to ensure effective oral hygiene.

The mean score for assessment was $14 \%$. All categories of patients received very poor care.

Assessment is necessary before a nursing diagnosis can be made.

Dependent and unconscious patients $(\mathrm{N}=27)$ scored $50 \%$ for planning which is poor nursing care. No indication in the patients' records could be found concerning proper planning instructions for mouth care.

Independent $(\mathrm{N}=27)$ patients scored $14 \%$.

Interdependent patients $(\mathrm{N}=27)$ scored $77 \%$ indicating good nursing care. 


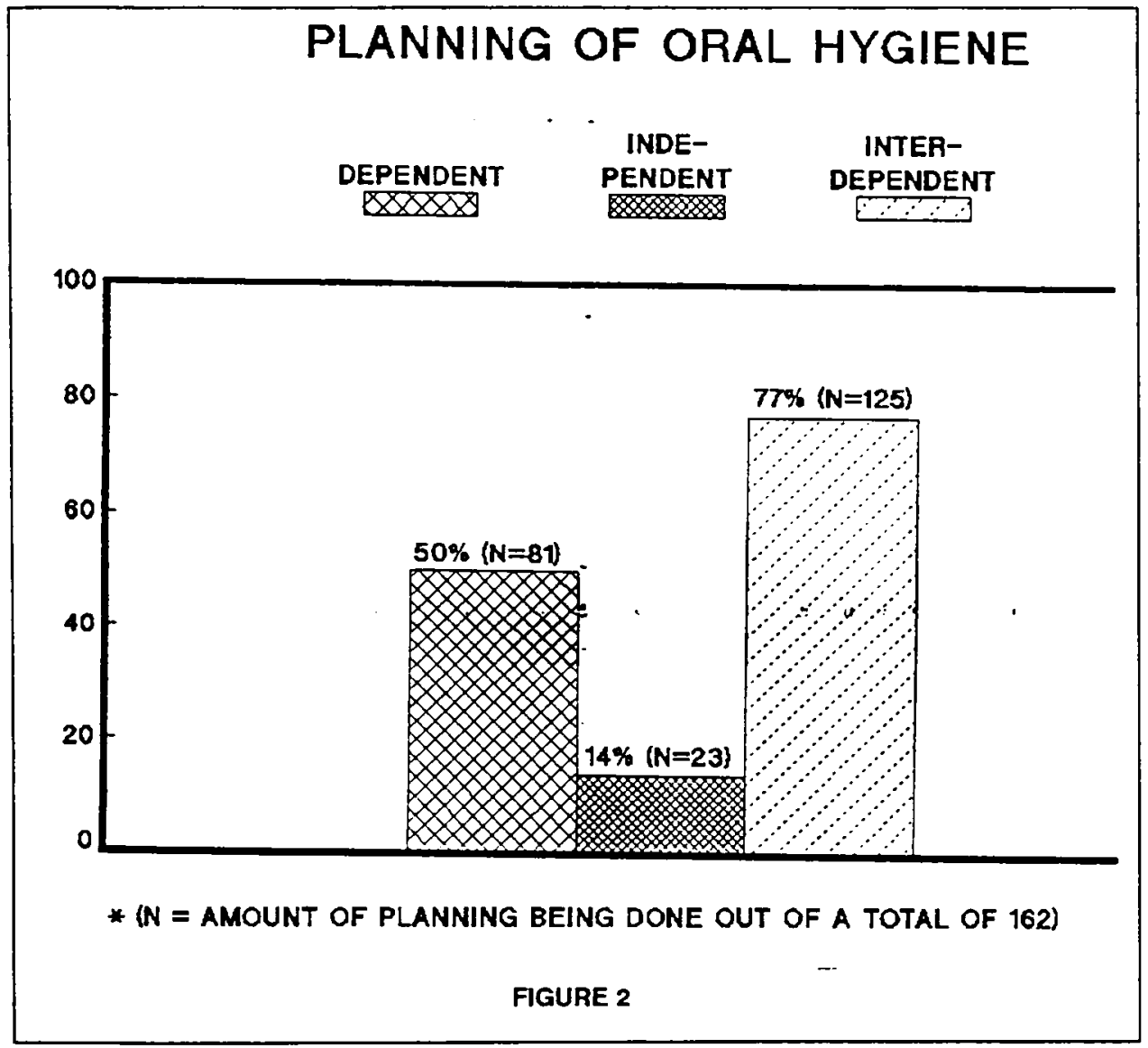

Nursing care must be communicated in writing or verbally after it has been carried out. The mean score for planning of nursing care is $47 \%$, which is poor care.

Figure 2: Shows these Scores.
An average of $24 \%$ was obtained for nursing care which indicates very poor implementation of oral hygiene.

Figure 3: Shows Scores for categores of patients.

Evaluation is an exceedingly important aspect of the nursing process because conclusions drawn from evaluation determine whether the nursing interventions can be terminated or have to be changed.

The total score for evaluation of mouth care rendered was $22 \%$ classified as very poor care.

It was found that 6 of the unconscious patients had sores on dry cracked lips, halitosis, dry furred coated tongue and dirty buccal cavities. Another six patients had dry cracked lips, dental caries, furred and coated tongues, dirty buccal cavities and halitosis. Of the dependent patients five patients had dry cracked lips, coated tongues and halitosis; three patients had dirty and coated buccal cavities, coated tongues and bleeding, swollen gums. The other seven patients' mouths were not so dirty.

\section{Figure 4: Shows Scores obtained}

The records of these $81(100 \%)$ patients were audited to determine whether mouthcare was recorded.

Figure 5 shows that this was badly done.

\section{LIMITATIONS OF THE STUDY}

These findings can thus not be generalised beyond this specific population group as sampling was non-random.

\section{RECOMMENDATIONS}

Ward Policy

Ward sisters should be reminded of the importance of ward policy conceming mouth care.

The findings showed that inadequate assessment regarding the condition of the mouth was done. Nurses must be taught to do relevant observations of the mouth, interpret the information gathered by observation and make a nursing diagnosis for planning of nursing care to the mouth and record the findings properly in the patient's record.

Planning should not be done without proper examination of the patient's mouth.

Mouth care must be given on a regular basis to dependent patients.

Demonstrations on proper mouth care techniques should be given on a regular basis.

Independent and interdependent patients should be assisted and advised concerning their mouth care.

Evaluation entails deciding whether actions planned and implemented are having the desired effect. This dimension presents many teaching opportunities. Aspects like the differences between a healthy and clean mouth must be 

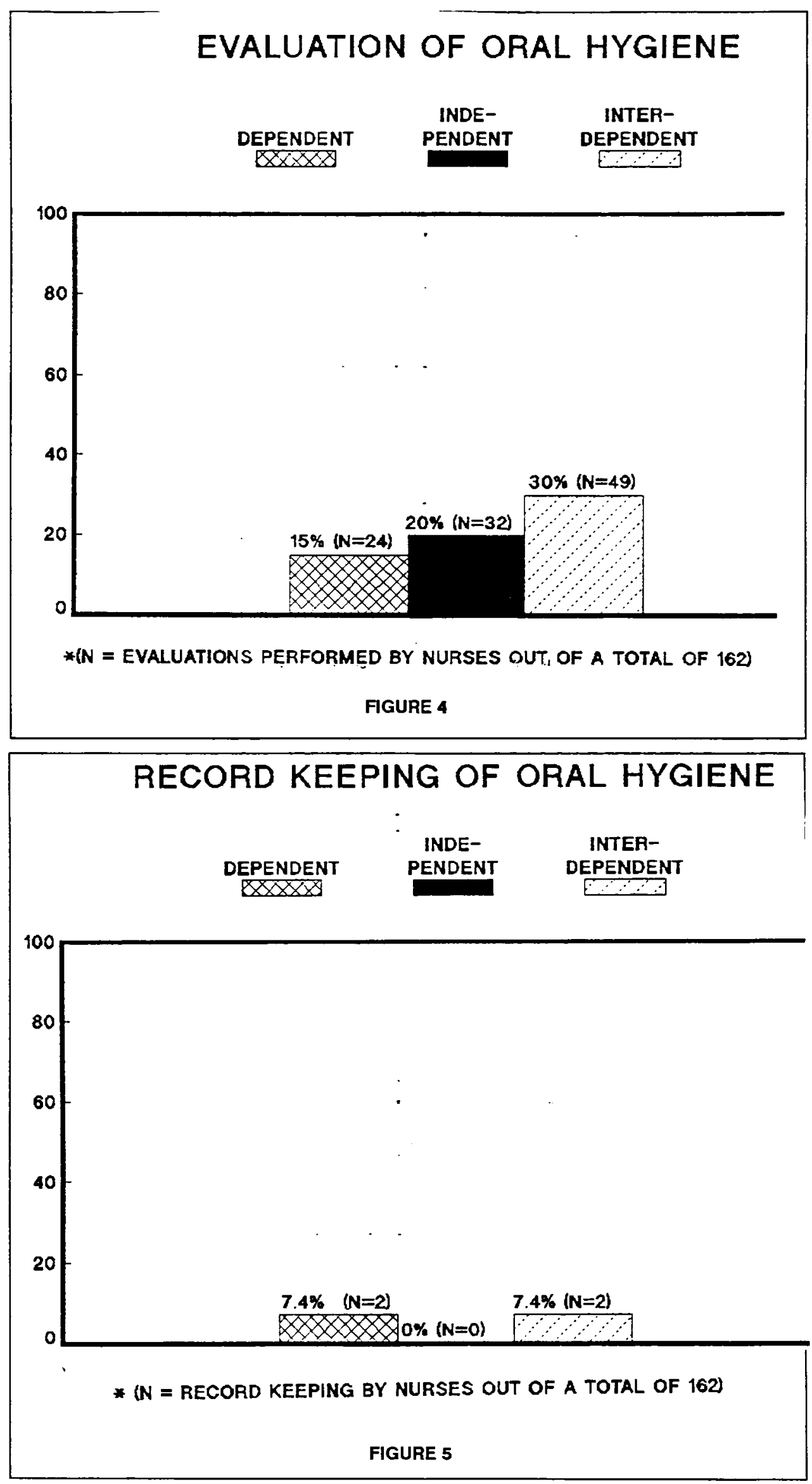

stressed in teaching. Evaluation of the effects of actions taken must be analised and recorded.

Recording of actions must be emphasised to nursing students.

The records of these $81(100 \%)$ patients were audited to determine whether mouthcare was recorded.

In service education should be given with regard to:

* the importance of record keeping

* the type of information required in the patient's record concerning mouth care.

* legal aspects regarding omission to give adequate care.

\section{CONCLUSION}

The question of how effective oral hygiene is for all categories of patients in a specific hospital was answered by the findings of this study, especially where it became evident that patients did not receive the very basic care to which they are entitled. Certain recommendations were made and if the recommendations could be implemented the quality of mouth care given to patients can improve to a high standard.

\section{REFERENCES}

Davies G.N. Primary oral health care for developing countries. World Health Forum Vol. 12 (1992)

Kozier, B. \& Erb, G. (1987): Fundamentals of nursing concepts \& procedures California: Addison-Wesley

Vlok, M.E. and Lochner, M.M. (1983): Manual of Basic Nursing Johannesburg: Juta and Co

A van Dyk (Professor)

LF Small

Faculty of Medical and Health Sciences University of Namibia 